\title{
Nachruf auf Peter Krahulec
}

Lieber Peter,

ich schreibe Dir, weil ich ganz sicher bin, dass Du auch ,im Himmel" so aufmerksam und zugewandt bist, dass Dich meine Worte dort erreichen. Wie gerne würde ich Dir alle meine folgenden Erinnerungen an Dich und ,an uns' persönlich sagen, aber Du bist jetzt tot - das ist eine Tatsache, mit der wir uns abfinden müssen, auch wenn uns das schwerfällt. Also sende ich Dir meine Anmerkungen über Dich ,hinterher', das ist ja schließlich der Sinn eines ,Nachrufs'.

Natürlich habe ich, als ich mich an diesen Nachruf gesetzt habe, zunächst ins Internet geguckt. Das ist ja heute so üblich. Da steht auf Deiner alten Homepage zu lesen: „1943 in Prag geboren; mit 3 Jahren im Viehwaggon nach Hessen gekommen; aufgewachsen auf dem Lande mit dem Verdikt der Dorfbewohner: die Flüchtlinge und die Wildschweine hätten ihnen gerade noch gefehlt; konservative Erziehung - Kleinstadtabitur; Studium der Philosophie, Soziologie, Germanistik und Geographie - in die „68er geraten“ - allmähliche Menschwerdung; ausgedehnte Reisen - Erstes und Zweites Staatsexamen - Referendariat und Tätigkeit in der Erwachsenen- und Lehrerbildung (PFI); Karriereplanung: als seinerzeit jüngster Professor in Hessen eingestellt - stark von den Neuen Sozialen Bewegungen (insbesondere Friedensbewegung) geprägt; aus verschiedenen Parteien und der katholischen Amtskirche ausgetreten; mache seither in einem verantwortlichen Sinne ,was ich will'; habe das Glück, mit einer Frau und drei Kindern zusammen zu leben und damit genug Grund unter den Füßen zu haben.“

Ja, so bist Du, so bist Du gewesen: Unpretentiös, präzise, mit dem Kopf in den Wolken und den Füßen auf der Erde. Ein Mann mit scharfem Verstand und großem Herzen - voller Energie und Engagement, gelebte Ethik und immer spürbare Menschenliebe.

Um zum Konkreten zu kommen, lieber Peter. Du warst an der Fachhochschule in Fulda Professor für Erziehungswissenschaft, Bildungs- Kultur- und Gemeinwesenarbeit sowie Geschichte Sozialer Arbeit und Pädagogik. Deine Forschungsgebiete waren: angewandte Friedenspädagogik, historischpolitische Bildung, Regionalentwicklung und ländliche Gemeinwesenarbeit sowie Soziale Bewegungen.

Sowohl in der Lehre als auch im Bereich der schulischen Bildung, vor allem aber im Bereich der Jugend- und Erwachsenenbildung, hast Du Dich immer wieder mit großem Engagement und richtungsweisenden methodischen Zugängen in den Themenbereich NS-Geschichte und Friedenspolitik hervorgetan. ,Buchenwald“ ist zu einem Deiner Lebensthemen geworden. Die ,Didaktik Buchenwald“ ist ohne Dich kaum zu denken. Überhaupt ist die ,Erinnerungsarbeit' im Allgemeinen von Dir immer wieder sowohl in der Theorie

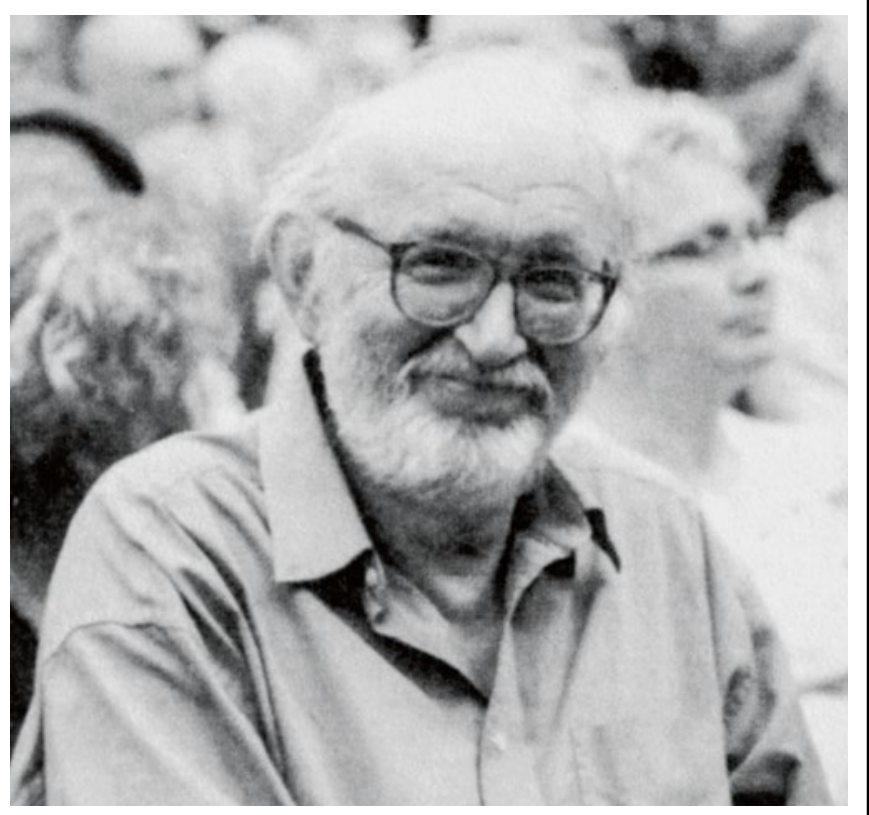

PETER KRAHULEC

als auch in der Praxis thematisiert und mit ,genialen' Ideen und Impulsen verwirklicht worden.

Wenn ich an Dich denke, fällt mit immer wieder ,ein Verfahren' ein, das mich besonders beeindruckt hat. Du hast häufig Prominente um Beiträge oder Unterstützung gebeten - so z.B. Ralph Giordano. Dem Anschreiben an diesen Personenkreis hast Du gerne ein Kärtchen angeheftet, auf dem stand: „Bitte ankreuzen: O ja gerne; O zu dem Zeitpunkt kann ich nicht; $O$ bitte belästigen Sie mich mit diesen Anfragen nie wieder". Ich bin sicher, dass Du nie eine Absage bekommen hast.

Wenn ich mir Deine umfangreiche Literaturliste angucke, muss ich feststellen, dass mir ein wichtiges Segment Deiner Aktivitäten nie wirklich in den Blick geraten ist: Deine lokalpolitischen, lokalhistorischen und ,heimatkundlichen ' Liebesbezeugungen an Fulda und das hessische Umfeld. Alle diejenigen, die Dich an die FH Fulda berufen haben, konnten nicht wissen, dass sie nicht nur einen hochengagierten Professor, sondern auch einen Lokalpatrioten ,eingekauft' haben - natürlich einen kritischen Lokalpatrioten, alles andere wäre ja keine Bereicherung für Hessen gewesen.

Also, lieber Peter, sorge auch im Himmel für Frieden und für soziale Gerechtigkeit - und vielleicht kannst Du denen auch mal sagen, dass sie sich endlich um ihre ,Vergangenheitsbewältigung، kümmern sollen.

Ich vermisse Dich - Deine Sabine

Sabine Hering 